\title{
Role of the atherogenic index of plasma in the prediction of the urinary albumin excretion and macrovascular complications in patients with type 2 diabetes
}

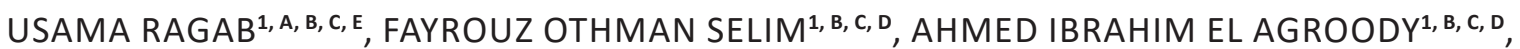 \\ ORCID ID: 0000-0001-5411-1943 \\ ORCID ID: 0000-0003-2155-9113 \\ MOHAMED HOSSAM ELDIN MOURAD ${ }^{2, c, D, ~ E}$, MOHAMED MOHAMED SAKR ${ }^{1, A, D, E, ~ F}$ \\ ${ }^{1}$ Internal Medicine Department, Faculty of Medicine, Zagazig University, Zagazig, Egypt \\ ${ }^{2}$ Clinical Pathology Department, Faculty of Medicine, Zagazig University, Zagazig, Egypt
}

A - Study Design, B - Data Collection, C - Statistical Analysis, D - Data Interpretation, E - Manuscript Preparation, F - Literature Search, G - Funds Collection

\begin{abstract}
Summary Background. Coexisting conditions with type 2 DM (T2DM), such as dyslipidemia and albuminuria, may lead to worsening of underlying diabetes and are strong risk factors for the development of cardiovascular disease.

Objectives. To identify the role of atherogenic index of plasma (AIP) as a marker for albuminuria and macrovascular complications in patients with T2DM.

Material and methods. We conducted a case-control study on 230 individuals who were classified into three groups. Group 1 ( $n=80$ ), T2DM patients who have macrovascular complications; Group $2(n=80)$, T2DM without macrovascular complications; While group 3 $(n=70)$ was healthy control. For all patients, laboratory investigations of lipid profile, urinary albumin execration and AIP were measured. The three study groups were compared. The relationship between AIP and urinary albumin excretion was investigated by correlation and regression analyses.

Results. AIP was significantly higher in T2DM patients with macrovascular complications compared to the other two groups $(p<0.001)$. There was a significant positive correlation between AIP and ACR $(r=0.740, p<0.001)$. AIP could significantly predict ACR even after adjustment for the DM duration, hsCRP, $\mathrm{HbA}_{1 \mathrm{c}}$ and $\mathrm{BMI}(\beta=321.47 ; p<0.0001)$. AIP could also predict macrovascular complications (unadjusted OR 547.3; $p<0.0001$ ), and it remains a significant predictor after adjustments (aOR 35.9; $p=0.005$ ). For the prediction of albuminuria in patients with diabetes, at a best cut off value of AIP ( $>0.137)$, the sensitivity and specificity were $80.51 \%$ and $90.48 \%$, respectively. Conclusions. High AIP was associated with an increased risk of albuminuria in patients with T2DM, which may contribute to the development of future macrovascular complications.

Key words: albuminuria, cardiovascular diseases, dyslipidemias, type 2 diabetes mellitus.
\end{abstract}

Ragab U, Selim FO, El Agroody AI, Mourad MHE, Sakr MM. Role of the atherogenic index of plasma in the prediction of the urinary albumin excretion and macrovascular complications in patients with type 2 diabetes. Fam Med Prim Care Rev 2020; 22(4): 312-318, doi: https://doi.org/10.5114/fmpcr.2020.100437.

\section{Background}

Diabetes mellitus (DM) has been recognized as a global issue, with approximately 425 million adults with diabetes globally, and an estimated one in two remains undiagnosed. In 2045, 693 million individuals aged 18-99, or 629 million individuals aged $20-79$, will have diabetes. Egypt ranks $8^{\text {th }}$ in the prevalence of diabetes according to the $8^{\text {th }}$ IDF diabetes atlas in 2017 and is anticipated to increase to $6^{\text {th }}$ position by 2045 [1].

Atherosclerotic cardiovascular disease (ASCVD) is the major cause of disability and death in patients with DM. Widespread coexisting diseases with type $2 \mathrm{DM}$, such as dyslipidemia, high blood pressure and endothelial dysfunction, are considered a risk for the development of ASCVD, with diabetes itself being a risk factor for ASCVD [2].

Dyslipidemia - a frequent risk factor for CVD - could be determined by lipid profile evaluation; it could also be greatly altered by currently available treatment. However, to define dyslipidemia in such classical ways, there are several obstacles, including their inability to identify particle sizes and lipoprotein subclasses [2].

Over the past decades, epidemiologists and clinicians have assessed that the risks of CVDs are based primarily on the fact that LDL-C is not optimal, particularly in those with intermediate risks. Many studies have revealed the significance of many lipid ratios or atherogenic indexes. Such indices were powerful CVD risk indicators owing to the discrepancy between atherogenic and antiatherogenic lipoproteins [3]. This represents the atherogenic index of plasma (AIP) calculated log10 (TG/HDL-C) and is allocated as a predictor for atherosclerosis and a surrogate of small dense low-density lipoprotein cholesterol (sdLDL-c) particle size and reflect HDL fractional esterification rate [4]. SdLDL - a subtype of $L D L-$ is the primary determinant of $L D L C$ atherogenicity. AIP, a useful proxy of sdLDL, has been stated as a stronger predictor of CVD risk than previously used parameters [5].

Albuminuria is linked to the development and progression of atherosclerotic cardiovascular disease, which could be explained by a common pathological mechanism, including endothelial dysfunction and chronic low-grade inflammation. It should be noted that the existence of albuminuria in patients with or without diabetes leads to increased cardiovascular morbidity and mortality [6].

\section{Objectives}

This study aimed to identify the role of AIP as a marker of albuminuria and macrovascular complications in patients with T2DM. 


\section{Material and methods}

We followed the Strengthening the Reporting of Observational Studies in Epidemiology (STROBE checklist) when writing this observational study, as endorsed by the EQUATOR network.

\section{Study design}

We designed a case-control study.

\section{Study population}

We included a total of 230 participants attending Zagazig University Hospitals, Egypt, within the period from January to June 2019.

\section{Study groups}

The study population was classified into three group :

- Group $1(n=80)$ included T2DM patients who have macrovascular complications.

- Group $2(n=80)$ included T2DM without macrovascular complications.

- Group $3(n=70)$ was a control group of healthy individuals without T2DM or any vascular complications.

\section{Inclusion criteria}

Patients meeting the following criteria were eligible for inclusion in this study:

1) age $>18$ years,

2) gender: patients of both sexes,

3) patients with confirmed T2DM (for group I and group II),

4) for group III, healthy individuals were considered.

\section{Exclusion criteria}

1) Patients admitted to the intensive care unit with acute illness, including patients with acute hyperglycemia crises, acute elevation in blood pressure, severe chest infections necessitating ventilatory support, septic shock, acute myocardial infarction, acute renal failure and any life threatening conditions.

2) Patients with serious chronic illness, including advanced, difficult to control chronic obstructive pulmonary disease, inflammatory bowel disease, inflammatory arthritis, connective tissue disorders with or without renal involvement, HIV/AIDS.

3) Patients with uncontrolled hypertension.

4) Decompensated liver cirrhosis whatever the etiology, including Child Pugh C, patients with previous liver transplantation, or patients with end stage liver disease.

5) Patients with advanced stage chronic kidney disease, estimated GFR $\leq 30 \mathrm{~mL} / \mathrm{min} / \mathrm{m}^{2}$ or patients receive renal replacement therapy.

6) Pregnancy.

7) Type $1 \mathrm{DM}$ or gestational DM.

\section{Case confirmation (confirmation of T2DM diagnosis)}

Diagnosis of T2DM was done according to the criteria of the American Diabetes Association [7]; the diagnosis is done based on the fasting plasma glucose level ( $\geq 126 \mathrm{mg} / \mathrm{dL}$ ) or 2-hour plasma glucose during oral glucose tolerance test $(\geq 200 \mathrm{mg} / \mathrm{dL}$ ) or hemoglobin $A_{1 c}$ of $\geq 6.5 \%$. Diagnosis requires two abnormal test results from the same sample or in two separate test samples.

\section{Selection of the control group}

The healthy individuals in the control group were selected from the preventive medicine clinic of Zagazig University Hospi- tals, Egypt. All participants in the control group were free from T2DM or any cardiovascular diseases.

\section{Clinical examination}

All patients were subjected to thorough clinical examination after taking a history, ECG, echocardiography, neuroradiologic investigations and Doppler ultrasound. General and local examination of various body systems with thorough cardiovascular examination was performed looking for evidence of chronic macrovascular disease.

\section{Laboratory investigations}

Routine laboratory investigations were conducted according to Zagazig University Hospital protocols of the clinical pathology laboratories and included the following:

1) complete blood count,

2) liver function tests,

3) kidney function tests,

4) hemoglobin $\mathrm{A}_{1 \mathrm{c}}\left(\mathrm{HbA}_{1 \mathrm{c}}\right)$ : done in the hospital laboratory and using a method that is NGSP certified and standardized to the DCCT assay,

5) Fasting Lipid profile (after 12 hours of fasting),

6) AIP: calculation of the atherogenic index of plasma (AIP) was done using the following formula $=\log _{10}(T G / H D L)$ in $\mathrm{mmol} / \mathrm{L}$ [5],

7) albuminuria (urinary albumin to creatinine ratio, $A C R$ ): we categorize our patients according to levels of albuminuria into three stages according to kidney disease improving global outcome (KDIGO): A1 (normal to mildly increased) with $\mathrm{ACR}<30 \mathrm{mg} / \mathrm{g}, \mathrm{A} 2$ (moderately increased) with ACR 30-300 mg/g and A3 (severely increased) with ACR $>300 \mathrm{mg} / \mathrm{g}$ [8]. We used the following system: Roche/Hitachi Cobas 600, (Cobas c501) for estimation of urinary albumin and creatinine.

\section{Diagnosis of macrovascular complications}

The presence or absence of CVD was established after a thorough history and complete physical examination. The assessment of macrovascular complications in the study population includes assessment of the following diseases:

1) $C A D$, including all the following: myocardial infarction, angina, procedures for revascularization, ischemic cardiomyopathy,

2) stroke, including either TIA or ischemic stroke (where the neurological deficit is framed or extends beyond 24 hours, respectively),

3) PAD, including intermittent claudication, lower limb gangrene, and revascularization procedures.

Patients with no CVD medical history, asymptomatic and with negative investigations were considered to have no macrovascular complications.

\section{Statistical analysis}

Categorical data was described as frequencies and percentages. Continuous data was described as mean (SD) or median (range) for normally and non-normally distributed data, respectively. Data normality was tested by the Kolmogorov-Smirnov test. For categorical variables, they were compared using the chi-square $\left(\chi^{2}\right)$. For comparisons of quantitative variables between the three groups, we used the one-way ANOVA or Kruskal-Wallis (KW) for normally and non-normally distributed data, respectively. A post-hoc Tukey-Kramer test was used if significant differences were found between three groups. For comparison between two groups, the independent sample $t$-test or the Mann-Whitney $U$ test for normally and non-normally distributed data, respectively, was used. 
The Pearson correlation coefficient was used to estimate the correlation between AIP, urinary AC, and other study parameters, if at least one of the two variables was normally distributed, while the rank correlation of Spearman was calculated to evaluate the correlations between the above parameters in case both the two correlating variables were not normally distributed.

We classified the study participants according to ACR into three subgroups. The three groups were compared to detect the significant confounders for inclusion in the multivariate analysis. Linear regression analysis was then used by both univariate and multivariate models (while adjusting for confounders) to evaluate the relation between AIP and ACR (numerical value). Multivariate logistic regression analysis was performed to assess the ability of AIP to predict diabetes-related macrovascular complications.

To determine the ability of the AIP to predict albuminuria or macrovascular complications, the receiver operating characteristic curve was designed to estimate the optimum cut off value, as well as the corresponding sensitivity and specificity. All analyses were done by MedCalc (version 15.8) and SPSS 20.0 for Windows (SPSS Inc., Chicago, Illinois, USA). A $p$-value $<0.05$ was considered as statistically significance.

\section{Ethical consideration}

This study was conducted in accordance with the Declaration of Helsinki. This study was approved by the Institutional Review Board of Faculty of Medicine, Zagazig University, Egypt. All participants were informed about the full details study, and they signed a written informed consent before participation in the study.

\section{Results}

\section{Description of the study population}

We included 230 participants. Of them, 140 were male (60.9\%) and 90 were female (39.1\%). Their mean age was $61 \pm 5$ years. The mean duration of diabetes in group I and II was 14.98 \pm 5.41 years. 41 (25.6\%) patients had $\mathrm{HbA}_{1 \mathrm{c}}$ below $7 \%$, and 119 (74.4\%) patients had $\mathrm{HbA}_{1 \mathrm{c}}$ above $7 \%$.

$\mathrm{HbA}_{1 \mathrm{c}}$ was higher in patients with diabetes with proven macrovascular complications (group ) compared to group II but without statistical significance. Other baseline characteristics of the three main groups are summarized in Table 1.

\begin{tabular}{|c|c|c|c|c|c|}
\hline & $\begin{array}{l}\text { Diabetes with macrovas- } \\
\text { cular complications } \\
(n=80)\end{array}$ & $\begin{array}{l}\text { Diabetes without macro- } \\
\text { vascular complications } \\
(n=80)\end{array}$ & $\begin{array}{l}\text { Control group } \\
(n=70)\end{array}$ & Test & $p$ \\
\hline $\begin{array}{l}\text { Age (years) } \\
\text { mean } \pm S D\end{array}$ & $61.92 \pm 4.16$ & $60.33 \pm 5.32$ & $60.77 \pm 5.39$ & $\begin{array}{l}F \\
2.19 \\
\end{array}$ & 0.115 \\
\hline $\begin{array}{l}\text { Gender } \\
\text { male 'No. (\%)' } \\
\text { female 'No. (\%)' }\end{array}$ & $\begin{array}{l}46(57.5 \%) \\
34(42.5 \%)\end{array}$ & $\begin{array}{l}44(55 \%) \\
36(45 \%)\end{array}$ & $\begin{array}{l}50(71.4 \%) \\
20(28.6 \%)\end{array}$ & $\begin{array}{l}\chi^{2} \\
4.82\end{array}$ & 0.09 \\
\hline $\begin{array}{l}\text { Smoking status } \\
\text { non-smoker 'No. (\%)' } \\
\text { smoker 'No. (\%)' }\end{array}$ & $\begin{array}{l}59(73.7 \%) \\
21(26.2 \%) \\
\end{array}$ & $\begin{array}{l}58(72.5 \%) \\
22(27.5 \%) \\
\end{array}$ & $\begin{array}{l}46(65.7 \%) \\
24(34.3 \%) \\
\end{array}$ & $\begin{array}{l}\chi^{2} \\
1.33\end{array}$ & 0.515 \\
\hline $\begin{array}{l}\text { Hypertension } \\
\text { no 'No. (\%)' } \\
\text { yes 'No. (\%)' }\end{array}$ & $\begin{array}{l}24(30 \%) \\
56(70 \%) \\
\end{array}$ & $\begin{array}{l}39(48.7 \%) \\
41(51.2 \%) \\
\end{array}$ & \begin{tabular}{|l|}
$70(100 \%)$ \\
$0(0 \%)$ \\
\end{tabular} & $\begin{array}{l}\chi^{2} \\
79.15\end{array}$ & $<0.001$ \\
\hline $\begin{array}{l}\text { hsCRP (mg/L) } \\
\text { median (range) }\end{array}$ & $9.59(3.30-15)$ & $4.54(0.55-19)$ & & $\begin{array}{l}\text { MW } \\
6.12 \\
\end{array}$ & $<0.001$ \\
\hline $\begin{array}{l}\text { DM duration (Years) } \\
\text { mean } \pm \text { SD }\end{array}$ & $15.63 \pm 5.98$ & $14.34 \pm 4.71$ & & \begin{tabular}{|l}
$\boldsymbol{t}$ \\
-1.51 \\
\end{tabular} & 0.133 \\
\hline $\begin{array}{l}\text { Serum albumin }(\mathrm{g} / \mathrm{dL}) \\
\text { mean } \pm \mathrm{SD}\end{array}$ & $3.55 \pm 0.61$ & $4.19 \pm 0.47$ & & $\begin{array}{l}\boldsymbol{t} \\
6.72 \\
\end{array}$ & $<0.001$ \\
\hline $\begin{array}{l}\text { Creatinine }(\mathrm{mg} / \mathrm{dL}) \\
\text { mean } \pm \text { SD }\end{array}$ & $1.12 \pm 0.3$ & $1.02 \pm 0.03$ & & $\begin{array}{l}t \\
-2.03 \\
\end{array}$ & 0.044 \\
\hline $\begin{array}{l}\mathrm{HbA}_{1 \mathrm{c}}(\%) \\
\quad \text { mean } \pm \mathrm{SD}\end{array}$ & $8.92 \pm 1.48$ & $8.52 \pm 2.05$ & & $\begin{array}{l}t \\
-1.14\end{array}$ & 0.258 \\
\hline
\end{tabular}

$\mathrm{DM}$ - diabetes mellitus, $\mathrm{HbA}_{1 \mathrm{c}}=$ hemoglobin $\mathrm{A}_{1 c^{\prime}}$ hsCRP - high sensitive C-reactive protein, $\mathrm{MW}$ - Mann-Whitney $\mathrm{U}$ test, $t$ - independent sample $(t)$ test, $\chi^{2}-$ chi-squared test.

\begin{tabular}{|c|c|c|c|c|c|c|}
\hline & $\begin{array}{l}\text { Diabetes with macrovas- } \\
\text { cular complications } \\
(n=80)\end{array}$ & $\begin{array}{l}\text { Diabetes without macro- } \\
\text { vascular complications } \\
(n=80)\end{array}$ & $\begin{array}{l}\text { Control } \\
(n=70)\end{array}$ & Test & $P 1$ & P2 \\
\hline $\begin{array}{l}\text { Total cholesterol }(\mathrm{mg} / \mathrm{dL}) \\
\text { mean } \pm \text { SD }\end{array}$ & $204.87 \pm 48.96$ & $215.23 \pm 32.76$ & $198.92 \pm 13.32$ & $\begin{array}{ll}F \\
4.09\end{array}$ & 0.018 & 0.118 \\
\hline $\begin{array}{l}\text { Triglycerides }(\mathrm{mg} / \mathrm{dL}) \\
\text { mean } \pm \mathrm{SD}\end{array}$ & $163.67 \pm 49.30$ & $154.79 \pm 45.71$ & $149.73 \pm 19.78$ & \begin{tabular}{|l|}
$\boldsymbol{F}$ \\
2.23
\end{tabular} & 0.11 & 0.239 \\
\hline $\begin{array}{c}\mathrm{HDL}-\mathrm{c}(\mathrm{mg} / \mathrm{dL}) \\
\text { mean } \pm \mathrm{SD}\end{array}$ & $33.63 \pm 9.42$ & $55.04 \pm 12.44$ & $61.83 \pm 9.30$ & \begin{tabular}{|l|}
$F$ \\
149.68 \\
\end{tabular} & $<0.001$ & $<0.001$ \\
\hline $\begin{array}{c}\text { LDL-c }(\mathrm{mg} / \mathrm{dL}) \\
\text { mean } \pm S D\end{array}$ & $138.50 \pm 47.98$ & $129.23 \pm 33.72$ & $107.14 \pm 14.87$ & \begin{tabular}{|l|}
$\boldsymbol{F}$ \\
15.12
\end{tabular} & $<0.001$ & 0.159 \\
\hline $\begin{array}{l}\text { AIP } \\
\text { mean } \pm \text { SD }\end{array}$ & $0.33 \pm 0.21$ & $0.08 \pm 0.19$ & $0.03 \pm 0.09$ & $\begin{array}{l}\boldsymbol{F} \\
66.23\end{array}$ & $<0.001$ & $<0.001$ \\
\hline
\end{tabular}




\begin{tabular}{|c|c|c|c|c|c|c|}
\hline & $\begin{array}{l}\text { Diabetes with macrovas- } \\
\text { cular complications } \\
(n=80)\end{array}$ & $\begin{array}{l}\text { Diabetes without macro- } \\
\text { vascular complications } \\
(n=80)\end{array}$ & $\begin{array}{l}\text { Control } \\
(n=70)\end{array}$ & Test & $P 1$ & P2 \\
\hline $\begin{array}{l}\text { AIP risk } \\
\quad \text { low risk } \\
\text { intermediate risk } \\
\text { high risk } \\
\end{array}$ & $\begin{array}{l}12(15 \%) \\
7(8.8 \%) \\
61(76.2 \%) \\
\end{array}$ & $\begin{array}{l}40(50 \%) \\
22(27.5 \%) \\
18(22.5 \%) \\
\end{array}$ & \begin{tabular}{|l|}
$59(84.3 \%)$ \\
$11(15.7 \%)$ \\
$0(0 \%)$ \\
\end{tabular} & $\begin{array}{l}x^{2} \\
113.67\end{array}$ & $<0.001$ & $<0.001$ \\
\hline $\begin{array}{l}\text { Non-HDL-c (mg/dL) } \\
\text { mean } \pm \text { SD }\end{array}$ & $171.24 \pm 48.31$ & $160.19 \pm 36.60$ & $137.08 \pm 15.25$ & $\begin{array}{l}F \\
16.60\end{array}$ & $<0.001$ & 0.105 \\
\hline
\end{tabular}

AIP - atherogenic index of plasma, F- one way ANOVA, HDL-c - high-density lipoprotein cholesterol, LDL-c - low-density lipoprotein cholesterol, $\chi^{2}$ - chi-squared test, $P 1$ - significance between three groups, $P 2$ - significance between patients with diabetes with or without macrovascular complications using independent sample $t$-test.

\section{Comparison of the AIP between the three study groups}

The comparison between the study groups in the lipid profile is shown in Table 2. An analysis of variance (ANOVA) on AIP yielded a significant difference among the three groups: $F(2$, $227)=66.23, p<0.001$. A post hoc Tukey-Kramer test showed that AIP was statistically significantly higher in group I $0.33 \pm$ $0.21)$ versus group II $(0.08 \pm 0.19)$ at $p<0.001$ and between group I and control group III $(0.03 \pm 0.09)$ at $p<0.001$, while there was no significant difference between group II and group III $(p=0.121)$. There was a statistically significant difference between the three study groups in terms of the AIP ( $p<$ $0.001)$. There was statistically significant difference between group I and group II as regards $\mathrm{HDL}-\mathrm{c}$, being lower in group I $(p<0.0001)$, while there was no statistically significant difference regarding total cholesterol $(p=0.118)$, triglycerides $(p=$ $0.239)$ or LDL-c ( $p=0.159)$ between group I and group II.

\section{Correlation between AIP and diabetes characteristics}

The correlation between AIP and other study parameters, including ACR, was tested using appropriate correlation analysis. Positive correlations between AIP and urinary ACR in patients with diabetes with or without macrovascular complications ( $n=80, r=0.641, p<0.001$ and $r=0.686, p<0.001$, respectively) were determined (Figure 1). Another correlation analysis between AIP and other study parameters is summarized in Table 3.
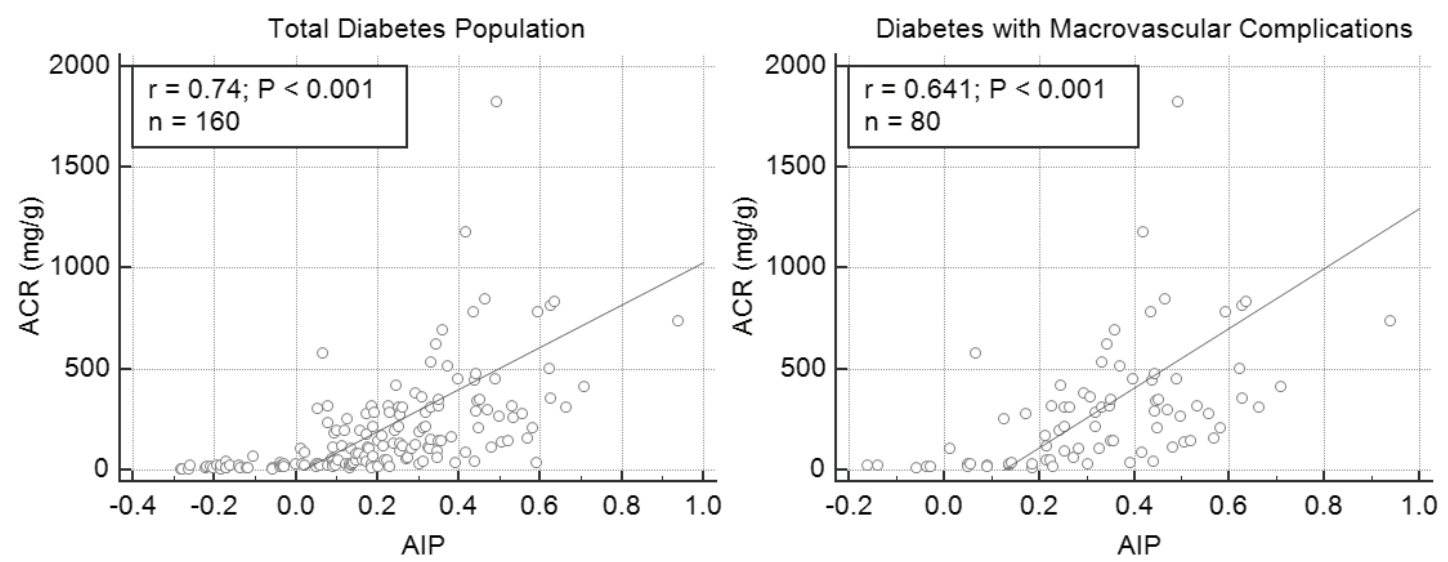

Figure 1. Correlation coefficient between both AIP and urinary albumin excretion determined by ACR in both total diabetes population and diabetic patients with proven macrovascular complications

\begin{tabular}{|c|c|c|c|c|c|c|}
\hline & \multicolumn{2}{|l|}{\begin{tabular}{|l|} 
Group I \\
$(n=80)$ \\
\end{tabular}} & \multicolumn{2}{|l|}{\begin{tabular}{|l|}
$\begin{array}{l}\text { Group II } \\
(n=80)\end{array}$ \\
\end{tabular}} & \multicolumn{2}{|c|}{\begin{tabular}{|l|}
$\begin{array}{l}\text { Total diabetic } \\
(n=160)\end{array}$ \\
\end{tabular}} \\
\hline & $r$ & $p$ & $r$ & $p$ & $r$ & $p$ \\
\hline Age & $0.104 *$ & 0.358 & $-0.061^{*}$ & 0.589 & $0.087^{*}$ & 0.191 \\
\hline $\mathrm{HbA}_{1 \mathrm{c}}$ & 0.096* & 0.499 & $0.161^{*}$ & 0.245 & $0.170 *$ & 0.081 \\
\hline ACR & $0.641^{* *}$ & $<0.001$ & $0.686^{* *}$ & $<0.001$ & $0.740 * *$ & $<0.001$ \\
\hline Total cholesterol & $-0.069 *$ & 0.544 & $0.313^{*}$ & 0.005 & 0.059* & 0.376 \\
\hline LDL-C & $-0.069 *$ & 0.539 & $0.354^{*}$ & 0.001 & $0.260 *$ & 0.001 \\
\hline Non-HDL-c & $0.081^{*}$ & 0.474 & $0.541^{* *}$ & $<0.001$ & $0.397^{*}$ & $<0.001$ \\
\hline hsCRP & $-0.16^{* *}$ & 0.157 & $0.533^{* *}$ & $<0.001$ & $0.615 * *$ & $<0.001$ \\
\hline DM duration & $0.424 * *$ & 0.001 & $0.042 * *$ & 0.709 & $0.284 * *$ & 0.001 \\
\hline $\mathrm{BMI}$ & $0.321 *$ & 0.004 & $0.388^{*}$ & 0.001 & $0.313^{*}$ & $<0.001$ \\
\hline $\mathrm{HbA}_{1 \mathrm{c}}$ & 0.096 & 0.499 & 0.161 & 0.245 & $0.17^{*}$ & 0.081 \\
\hline
\end{tabular}

* Pearson correlation coefficient, ** Spearman's coefficient of rank correlation, a $p$-value $<0.05$ was considered statistically significant, ACR - albumin to creatinine ratio, $\mathrm{BMI}$ - body mass index, $\mathrm{DM}$ - diabetes mellitus, $\mathrm{HbA}_{1 c}$ - hemoglobin $\mathrm{A}_{1 c^{\prime}} \mathrm{HDL}-\mathrm{c}$ - high-density lipoprotein cholesterol, hsCRP - high sensitive C-reactive protein, LDL-c - low-density lipoprotein cholesterol. 


\section{Results of the regression analysis}

A significant relationship between the ACR (as the dependent variable) and the AIP $(B=378.99 ; p<0.001)$ by using univariate linear regression analysis. In a multivariate regression model adjusting for DM duration, hsCRP, $\mathrm{HbA}_{1 c}$, and $\mathrm{BMI}$, AIP could still have the ability to predict ACR together with DM duration. In this adjusted model, the adjusted $B$ coefficient for AIP was $321.47(p<0.001)$.

In the univariate logistic regression analysis, AIP was the lipid parameter that was most strongly associated with a macrovascular complication with an unadjusted OR of $547.38(p<0.001)$ (Table 4). This association persisted after adjustments for some CVD risk factors (HTN status, albuminuria, hsCRP, and DM duration in years) (Table 5).

\begin{tabular}{|c|c|c|c|c|}
\hline Variables & Coefficients $B$ & OR & $95 \% \mathrm{Cl}$ & $p$ \\
\hline TC & -0.006 & 0.99 & $0.986-1.002$ & 0.123 \\
\hline LDL-C & 0.005 & 1.01 & $0.998-1.013$ & 0.161 \\
\hline Non-HDL & 0.006 & 1.006 & 0.999-1.014 & 0.106 \\
\hline HDL & -0.186 & 0.83 & $0.783-0.879$ & $<0.001$ \\
\hline TG & 0.004 & 1.004 & 0.997-1.011 & 0.239 \\
\hline AIP & 6.31 & 547.38 & $62.99-4756.43$ & $<0.001$ \\
\hline
\end{tabular}

$\mathrm{OR}$ - odds ratio.

\begin{tabular}{|c|c|c|c|}
\hline \multirow[t]{2}{*}{ Variable } & \multicolumn{3}{|c|}{ Adjusted Model* } \\
\hline & Adjusted OR & $95 \% \mathrm{Cl}$ & $p$ \\
\hline AIP & 35.98 & $2.92-444.18$ & 0.005 \\
\hline $\mathrm{HDL}$ & 0.84 & $0.793-0.893$ & $<0.001$ \\
\hline
\end{tabular}

* Adjusted for albuminuria, HTN, hsCRP and diabetes duration.

\section{Role of AIP in the prediction of albuminuria and macrovascular complications}

For the prediction of albuminuria in patients with diabetes, at a best cut off value of AIP ( $>0.137)$, the sensitivity and specificity were $80.51 \%$ and $90.48 \%$, respectively, with an AUC of $93 \%$ (Figure 2). For the prediction of CVD in patients with diabetes, at a best cut off value of AIP ( $>0.2007)$, the sensitivity and specificity were $76.25 \%$ and $77.5 \%$, respectively, with an AUC of $81 \%$.
Figure 2. ROC curve analysis to determine the best cut off value used to predict CVD in patients with diabetes

\section{Discussion}

\section{Significance of the study}

We cannot disregard the important impact of dyslipidemia in patients with DM and the risk of macrovascular complications that increase considerably when complications related to diabetes occur. Despite the multifactorial and heterogeneous pathogenesis of macrovascular complications in DM, dyslipidemia is found to be a strong predictor and to be regarded as a significant risk factor in this population [4].

AIP that could be readily calculated from the standard lipid profile can function as a complement that adds considerably further predictive value for cardiovascular events than the individual lipid parameters. This is a critical index that can be used as a stand-alone index $[9,10]$ to predict cardiovascular risk. The main issue addressed in this study was whether AIP in patients with diabetes is an independent risk factor for prediction of albuminuria in patients with diabetes and whether it is related to the presence of diabetes-related macrovascular diseases.

\section{Summary of the study findings}

Our study showed that AIP was higher in patients with diabetes with macrovascular complications compared to those without. According to some authors, calculating AIP may be more accurate in anticipating the risk of developing atherosclerotic CVD in patients with DM. This parameter can be readily calculated whenever a lipid profile is ordered to evaluate the cardiovascular risk of the patient [11]. Nimmanapalli et al. observed that AIP is considerably increased in patients with diabetes compared to control and is substantially high in patients with diabetes-related macrovascular complications, suggesting that AIP may represent atherogenic dyslipidemia [12].

In contrast to those without macrovascular complication, AIP was statistically significantly higher in patients with diabetes-related macrovascular complications, but other lipid parameters, including total cholesterol, triglycerides and LDL-c, were not significantly different between the two groups. This may indicate the capacity of AIP to function separately from other lipid parameters to predict atherosclerosis and to act as a surrogate for a powerful predictor of future atherosclerosis [5]. This can illustrate the significance of many lipid ratios, particularly AIP, in optimizing the predictive power of the lipid profile.

Dobiášová and Frohlich proposed that AIP values below 0.11 have been associated with low cardiovascular risk (CV), whereas values between 0.11 and 0.21 indicated intermediate CV risk, and $>0.21$ indicated high CV risk [13]. In our study, as previously, we stratified our patients into three groups, and patients with higher AIP values were found to have more percentage of hypertension and to have a longer duration of diabetes. It is known that the factors mentioned above have a significant impact on the development and progression of chronic macrovascular complications and are known to be risk factors for CVD [14].

In our study, there was a statistically significant correlation between AIP in patients with diabetes and ACR, TC, LDL-c, hsCRP, $\mathrm{BMI}$ and diabetes mellitus duration. Regmi et al. assessed the usefulness of AIP in the diabetic and prediabetic population for future CVD prediction, reporting that AIP correlates with fasting total cholesterol $(p=0.09)$, high TG $(p=0.002)$, increased LDL $(p=0.001)$, non-HDL $(p=0.005)$, decreased HDL $(p<0.0)$ and increased hsCRP $(p<0.001)$. Contrary to this, Hartopo et al. investigated the role of AIP in predicting major adverse cardiovascular events with a low AIP value $(<0.24)$ as an independent predictor for all causal mortality in patients suffering from acute myocardial infarction requiring intensive care hospitalization [15].

No statistically significant association between $\mathrm{HbA}_{1 \mathrm{c}}$ and AIP was found in our study. In a study by Anjum et al., a significant and positive associations of AIP with $\mathrm{HbA}_{1 \mathrm{c}}(r=0.123$, 
$p=0.033$ ) was found [16]. They also stated that the effect of sustained hyperglycemia and insulin resistance, which increases lipogenesis - marked by increasing levels of TG along with low levels of HDL-C - could contribute to elevated levels of AIP in patients with diabetes.

Many studies assessed the utility of other lipid ratios, and it was found that AIP is the most sensitive marker compared to other atherogenic indicators, such as Castelli's risk index-I (TC/ /HDL-C), Castelli's risk index-II (LDL-C/HDL-C) and the atherogenic coefficient (TC-HDL-C/HDL-C). As mentioned before, AIP includes TG in its equation, which is characteristically elevated in patients with T2DM, which makes AIP a more suitable and better indicator for diabetic dyslipidemia. In addition, AIP was found to be associated with other CVD risk factors [17].

In our study, patients with albuminuria had a statistically significant high AIP value compared to those with no albuminuria. Suchitra et al. found that higher values of AIP, together with low HDL levels, were observed in patients with type $2 \mathrm{DM}$ with or without nephropathy when compared to controls., AIP was also higher in patients with diabetic nephropathy when compared to diabetic patients without kidney affection ( $0.61 \mathrm{vs}$ $0.52, p<0.05$ ) [18]. In another study, it was found that ACR was statistically significantly higher in those with high AIP $(>0.21)$ compared to those with lower values of AIP ( $\mathrm{mdn}=12.65$ vs 7.05 and 8.21). A positive correlation was also determined between AIP and ACR $(r=0.176, p<0.001)$ [3].

Other studies assessed the relationship between AIP and diabetic nephropathy in patients with type 2 diabetes mellitus, which indicated that patients with type 2 DM and elevated AIP are at higher risk for albuminuria and that AIP is an early determinant for the development of diabetic nephropathy [19].

Both diabetes and chronic kidney disease are linked to various forms of dyslipidemia, hypertriglyceridemia reduced HDL-c and higher small dense low-density lipoprotein cholesterol (sdLDL-c). An association between dyslipidemia and albuminuria was also determined. Dyslipidemia associated glomerular atherosclerosis and tubulointerstitial fibrosis are proposed factors that play a crucial role in the development and progression of albuminuria and diabetic nephropathy [20].

There was a significant relationship between ACR and AIP, in univariate linear regression analysis, which was further confirmed after further multivariate analysis adjusted for DM duration, hsCRP, $\mathrm{HbA}_{1}$, and $\mathrm{BMI}$. The presence of albuminuria in patients with or without diabetes is linked to increased cardiovascular mortality. Albuminuria itself has been related to the development of ASCVD due to endothelial dysfunction with ad- vanced procoagulant imbalance and chronic low-grade inflammation [21].

In this regard, our study shows that there was a statistically significant difference as regard ACR between a patient with diabetes and macrovascular complications versus those without macrovascular complications. Any degree of albuminuria is a risk factor for $\mathrm{CV}$ events in patients with or without $\mathrm{DM}$; the risk increases with increased levels of ACR, starting even below the microalbuminuria cutoff [22].

In the univariate logistic regression analysis, AIP was the lipid parameter that was most strongly associated with a macrovascular complication with an unadjusted OR of 547.38 ( $p<$ 0.001 ). This association persisted after adjustments for some CVD risk factors (HTN status, albuminuria, hsCR, and DM duration in years).

\section{Strength points and limitations}

Our study has several strength point: first, the relatively large sample size of the study; secondly, we included three groups of participants, including T2DM patients with macrovascular complications, T2DM patients without macrovascular complication, and healthy control; thirdly, we analyzed the ability of AIP to predict albuminuria and macrovascular complications after adjusting for other factors in the multivariate regression analysis. Nonetheless, our study has a few limitations. As it is a retrospective study, the process of retrospective data collection may leave out some variables. Secondly, it involves a single institution and may not represent the general population. Our study results regarding the logistic regression model should also be adjusted for other CVD risks, including smoking and family history of CVD. It also needs to be adjusted for drugs that could affect urinary albumin execretion, such as renin-angiotensin system blockers.

\section{Conclusions}

In conclusion, high AIP was associated with an increased risk of CVD and the development of albuminuria in patients with diabetes, and this may contribute to an added risk for the development of future macrovascular complications. It is of note that, at first glance, it is possible to be misled by analyzing conventional lipid parameters, as they may be normal, but the patients may still be at risk of developing CVD. This parameter can be easily calculated whenever a lipid profile is requested to assess the patient's cardiovascular risk.

Source of funding: This work was funded from the authors' own resources.

Conflicts of interest: The authors declare no conflicts of interest.

\section{References}

1. International Diabetes Federation. IDF Diabetes Atlas. 8th ed. Brussels: International Diabetes Federation, 2017. Available from URL: http://www.diabetesatlas.org.

2. American Diabetes Association. 10. Cardiovascular disease and risk management: standards of medical care in diabetes - 2019. Diabetes Care 2019; 42(Suppl. 1): S103-S123.

3. Akbas EM, Timuroglu A, Ozcicek A, et al. Association of uric acid, atherogenic index of plasma and albuminuria in diabetes mellitus. Int J Clin Exp Med 2014; 7(12): 5737-5743.

4. Millán J, Pintó X, Muñoz A, et al. Lipoprotein ratios: physiological significance and clinical usefulness in cardiovascular prevention. Vasc Health Risk Manag 2009; 5: 757-765.

5. Dobiášová M, Frohlich J, Šedová M, et al. Cholesterol esterification and atherogenic index of plasma correlate with lipoprotein size and findings on coronary angiography. J Lipid Res 2011; 52(3): 566-571.

6. Wang Y, Yuan A, Yu C. Correlation between microalbuminuria and cardiovascular events. Int J Clin Exp Med 2013; 6(10): 973-978.

7. American Diabetes Association. 2. Classification and Diagnosis of Diabetes: Standards of Medical Care in Diabetes - 2019. Diabetes Care 2019; 42(Suppl. 1): S13-S28.

8. Levin A, Stevens PE, Bilous RW, et al. Kidney disease: Improving Global Outcomes (KDIGO) CKD Work Group. KDIGO 2012 clinical practice guideline for the evaluation and management of chronic kidney disease. Kidney Int Supp/ 2013; 3(1): 1-50.

9. Bhardwaj S, Bhattacharjee J, Bhatnagar MK, et al. Atherogenic index of plasma, castelli risk index and atherogenic coefficient-new parameters in assessing cardiovascular risk. Int J Pharm Biol Sci 2013; 3(3): 359-364. 
10. Khazaál MS. Atherogenic index of plasma (AIP) as a parameter in predicting cardiovascular risk in males compared to the conventional dyslipidemic indices (cholesterol ratios). Kerbala Jorunal of Medicine 2013; 6(1): 1506-1513.

11. Adu EM, Ukwamedu HA, Oghagbon ES. Assessment of cardiovascular risk indices in type 2 diabetes mellitus. Trop Med Surg 2015; 3(184): $1-4$.

12. Nimmanapalli HD, Kasi AD, Devapatla PK, et al. Lipid ratios, atherogenic coefficient and atherogenic index of plasma as parameters in assessing cardiovascular risk in type 2 diabetes mellitus. Int J Res Med Sci 2016; 4(7): 2863-2869.

13. Dobiášová $M$, Frohlich J. The plasma parameter log (TG/HDL-C) as an atherogenic index: correlation with lipoprotein particle size and esterification rate in apob-lipoprotein-depleted plasma (FERHDL). Clin Biochem 2001; 34(7): 583-588.

14. Ridker PM, Danielson E, Fonseca FA, et al. Reduction in C-reactive protein and LDL cholesterol and cardiovascular event rates after initiation of rosuvastatin: a prospective study of the JUPITER trial. Lancet 2009; 373(9670): 1175-1182.

15. Regmi $\mathrm{P}$, Baral $\mathrm{B}$, Raut $\mathrm{M}$, et al. Atherogenic index of plasma for prediction of future cardiovascular disease in prediabetes and diabetes population. Atherosclerosis 2016; 252: e120, doi: 10.1016/j.atherosclerosis.2016.07.636.

16. Anjum M, Uddin MS, Tamanna NA, et al. Evaluation of lipid profile pattern and atherogenic index of plasma (AIP) having type-2 diabetes mellitus in Bangladesh. Int J Res Med Sci 2018 6(3): 776-783.

17. Bo MS, Cheah WL, Lwin S, et al. Understanding the relationship between atherogenic index of plasma and cardiovascular disease risk factors among staff of an University in Malaysia. J Nutr Metab 2018; 2018: 7027624, doi: 10.1155/2018/7027624.

18. Suchitra MM, Sheshu KM, Bitla AR, et al. Atherogenic dyslipidemia in diabetic nephropathy: lipoprotein (a), lipid ratios and atherogenic index. Int J Res Med Sci 2013; 1(4): 455-459.

19. Jia L, Wei Z, Yajing Z, et al. Relationship between atherogenic index of plasma and diabetic nephropathy in patients with type 2 diabetes mellitus. Chin J Clin 2014; 14: 2570-2573.

20. Hung CC, Tsai JC, Kuo HT, et al. Dyslipoproteinemia and impairment of renal function in diabetic kidney disease: an analysis of animal studies, observational studies, and clinical trials. Rev Diabet Stud 2013; 10: 110-120.

21. Leon BM, Maddox TM. Diabetes and cardiovascular disease: epidemiology, biological mechanisms, treatment recommendations and future research. World J Diabetes 2015; 6(13): 1246-1258.

22. Gerstein $\mathrm{HC}$, Mann JF, Yi Q, et al. Albuminuria and risk of cardiovascular events, death, and heart failure in diabetic and nondiabetic individuals. JAMA 2001; 286(4): 421-426.

Tables: 5

Figures: 2

References: 22

Received: 25.11.2019

Reviewed: 8.12.2019

Accepted: 27.01.2020

Address for correspondence:

Usama Ragab, MD

Faculty of Medicine

Zagazig University

Zagazig

Egypt

Tel.: 00201000035863

E-mail: usama.ragab.zu@gmail.com, usamaragab@medicine.zu.edu.eg 